\title{
Gastric Outlet and Duodenal Obstruction as a Complication of Migrated Gastrostomy Tube: Report of Two Cases and Literature Review
}

\author{
Jamil Shah ${ }^{\mathrm{a}}$, Tagore Sunkara ${ }^{\mathrm{a}, \mathrm{e}}$, Krishna Sowjanya Yarlagadda ${ }^{\mathrm{b}}$, \\ Prashanth Rawlac ${ }^{\mathrm{c}}$, Vinaya Gaduputi ${ }^{\mathrm{d}}$
}

\begin{abstract}
Percutaneous endoscopic gastrostomy (PEG) is a well-recognized procedure for providing enteral feeding and long-term enteral nutritional support. Although it is mostly well tolerated, complications, sometimes mechanical in nature, do occur. Rare, and often initially unrecognized, late complications of PEG tube placement are gastric outlet obstruction and duodenal obstruction. Simple adjustment of the gastrostomy tube will lead to the improvement of the patient's clinical condition and prevent further complications. Physicians should be aware of and suspect gastric outlet and duodenal obstruction as rare late complications of PEG tube placement. Simple adjustment of the gastrostomy tube can resolve the problem without unnecessary medical tests and overly aggressive care. Here, we present two interesting cases of elderly women who developed mechanical obstruction after inadvertent migration of the gastrostomy tube.
\end{abstract}

Keywords: Percutaneous endoscopic gastrostomy; PEG; Gastrostomy; Complications of PEG; Gastric outlet obstruction; Duodenal obstruction

\section{Introduction}

Percutaneous endoscopic gastrostomy (PEG) is a well-recognized procedure for providing enteral feeding to those with

Manuscript submitted December 27, 2017, accepted January 18, 2018

aDivision of Gastroenterology and Hepatology, The Brooklyn Hospital Center, 121 Dekalb Ave, Brooklyn, NY 11201, USA

bDepartment of Internal Medicine, Southwest Community Health Center, Bridgeport, CT 06605, USA

'Department of Internal Medicine, Memorial Hospital of Martinsville and Henry County, Martinsville, VA 24115, USA

dDepartment of Internal Medicine, SBH Health System, 4422 Third Ave, Bronx, NY 10457, USA

${ }^{e}$ Corresponding Author: Tagore Sunkara, The Brooklyn Hospital Center, Clinical Affiliate of Mount Sinai Hospital, 121 Dekalb Avenue, Brooklyn, NY 11201, USA. Email: tagoresunkara@hotmail.com

doi: https://doi.org/10.14740/gr954w swallowing disorders as well as long-term enteral nutritional support to those who need it. Across the world, the procedure has become commonly utilized. The gastrostomy tube is a relatively safe and effective means through which to provide nourishment, water, and medications directly into the lumen of the stomach. Although PEG tube placement is mostly well tolerated, complications, sometimes mechanical in nature, do occur. Rare, and often initially unrecognized, late complications include gastric outlet obstruction, a syndrome characterized by epigastric pain and postprandial vomiting secondary to mechanical obstruction. In this setting, the gastrostomy tube migrates forward into the pyloric channel or the duodenal bulb [1]. Another late complication is duodenal obstruction, where the gastrostomy tube can migrate as far as the second part of the duodenum [1]. Risk factors for these occurrences include the migration of an external bolster away from the abdominal wall, the migration of an inflated balloon (in the case of balloon gastrostomy tubes) through the pyloric channel, and the placement of the gastrostomy tube close to the pylorus [2]. In clinical practice, the presentation is often misidentified as small bowel obstruction, leading to unnecessary medical tests and overly aggressive care.

\section{Case Report}

\section{Case 1}

A 75-year-old woman living in a nursing home, with past medical history of multiple strokes, hypertension, hyperlipidemia, diabetes mellitus, osteoporosis, mental retardation, and PEG tube placement secondary to dysphagia from stroke 3 years earlier, presented to the emergency department with abdominal discomfort and six episodes of non-bloody, nonbilious vomiting over the preceding $24 \mathrm{~h}$. Two days earlier, she had complained of itching around the location of the gastrostomy tube and was seen repeatedly pulling on the external component of the device. At presentation, the patient appeared clinically dehydrated. She was hemodynamically stable (heart rate 95 beats/min, blood pressure $105 / 70 \mathrm{~mm} \mathrm{Hg}$ ) and afebrile (temperature $36.3{ }^{\circ} \mathrm{C}$ ). On physical exam, the abdomen was distended (Fig. 1a) with tenderness in the epigastric area and hypoactive bowel sounds. There was no guarding or rigid- 

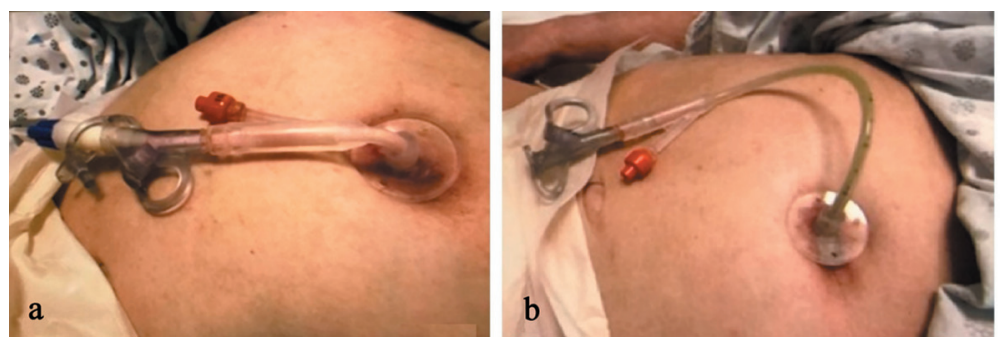

Figure 1. (a) The patient's distended abdomen with migrated gastrostomy tube causing gastric outlet obstruction. (b) The patient's abdomen with gastrostomy tube after appropriate adjustment.

ity. Aggressive intravenous hydration with normal saline was started.

Laboratory testing was performed and showed hemoglobin of $16.2 \mathrm{~g} / \mathrm{dL}(13.5-17.5 \mathrm{~g} / \mathrm{dL})$, hematocrit of $47.2 \%$ (40-52\%), white blood cell count of $11.5 \times 10^{9} / \mathrm{L}(4.0-11.0$ $\left.\times 10^{9} / \mathrm{L}\right)$, platelet count of $418 \times 10^{9} / \mathrm{L}\left(150-450 \times 10^{9} / \mathrm{L}\right)$, sodium of $143 \mathrm{mEq} / \mathrm{L}(135-145 \mathrm{mEq} / \mathrm{L})$, potassium of 3.7 $\mathrm{mEq} / \mathrm{L}(3.5-5.0 \mathrm{mEq} / \mathrm{L})$, chloride of $95 \mathrm{mEq} / \mathrm{L}(96-110$ $\mathrm{mEq} / \mathrm{L})$, blood urea nitrogen of $35 \mathrm{mg} / \mathrm{dL}(7-22 \mathrm{mg} / \mathrm{dL})$, creatinine of $1.6 \mathrm{mg} / \mathrm{dL}(0.6-1.3 \mathrm{mg} / \mathrm{dL})$, glucose of $135 \mathrm{mg} /$ $\mathrm{dL}$, and calcium of $10.2 \mathrm{mg} / \mathrm{dL}(8.5-10.5 \mathrm{mg} / \mathrm{dL})$. The liver function tests were normal. Computed tomography (CT) scan of the abdomen was performed and showed that the internal inflated balloon of the gastrostomy tube had migrated distally and had become impacted in the pyloric channel, thus producing a functional gastric outlet obstruction.

The gastrostomy tube was pulled back, withdrawn into the stomach and secured to the abdominal wall with the help of the external bumper at $2.5 \mathrm{~cm}$. Abdominal distention was improved after the PEG tube adjustment (Fig. 1b). Enteral feeding was successfully resumed. Over the next several days, the patient's clinical condition improved and the patient's laboratory parameters normalized.

\section{Case 2}

A 59-year-old woman who was a resident of an acute nursing care facility, with past medical history of amyotrophic lateral sclerosis and PEG tube placement 2 years earlier, began to complain of upper abdominal discomfort and experienced three episodes of vomiting, one morning. The vomitus consisted of bilious fluid. Prior to her symptoms, she was fed regularly via gastrostomy tube, which had been functioning well. At presentation, the patient appeared clinically dehydrated. She was hemodynamically stable (heart rate 102 beats $/ \mathrm{min}$, blood pressure $111 / 60 \mathrm{~mm} \mathrm{Hg}$ ) and afebrile (temperature $36.6{ }^{\circ} \mathrm{C}$ ). On physical exam, the abdomen was soft and not distended with no tenderness and normoactive bowel sounds. There was no guarding or rigidity. Aggressive intravenous hydration was started. Laboratory testing was performed and was remarkable for hypochloremia with chloride of $92 \mathrm{mEq} / \mathrm{L}$ (96 - 110 $\mathrm{mEq} / \mathrm{L})$ and hypokalemia with potassium of $3.3 \mathrm{mEq} / \mathrm{L}(3.5$ - $5.0 \mathrm{mEq} / \mathrm{L}$ ). A gastroenterologist was consulted who recommended PEG gastrograffin study which confirmed the presence of the gastrostomy tube in the duodenum with no contrast seen in the stomach (Fig. 2a).

Then, the gastrostomy tube was repositioned by deflating the internal balloon, pulling back and withdrawing the gastrostomy tube into the stomach, inflating the internal balloon again and securing it with an external bumper at $2 \mathrm{~cm}$. Enteral feeding was successfully resumed almost immediately. Over the next several days, the patient's clinical condition improved and the patient's laboratory parameters normalized. A repeat PEG gastrograffin study was performed which showed contrast in the stomach and the duodenum which confirmed the tip of the gastrostomy tube in the stomach (Fig. 2b).

\section{Discussion}

The gastrostomy tube is a relatively safe and effective means
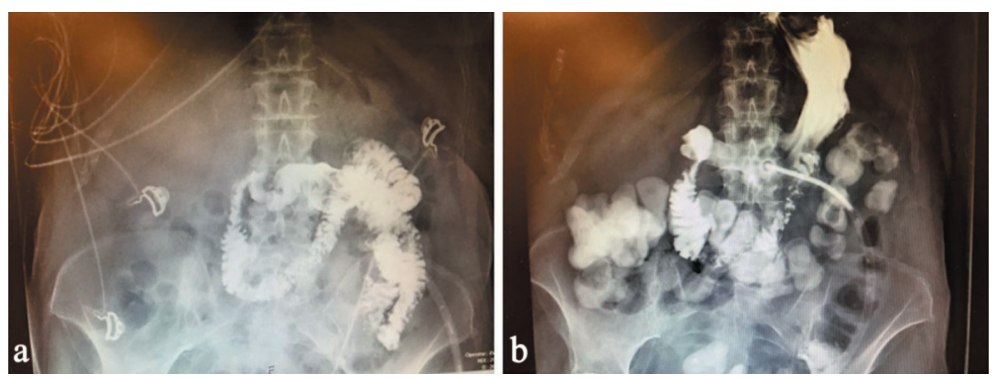

Figure 2. (a) PEG gastrograffin study visualized the small bowel and not the stomach, which confirmed the presence of the gastrostomy tube in the duodenum causing duodenal obstruction. (b) PEG gastrograffin study, after appropriate adjustment of the gastrostomy tube, visualized both the stomach and the small bowel, confirming the presence of the gastrostomy tube in the stomach. 


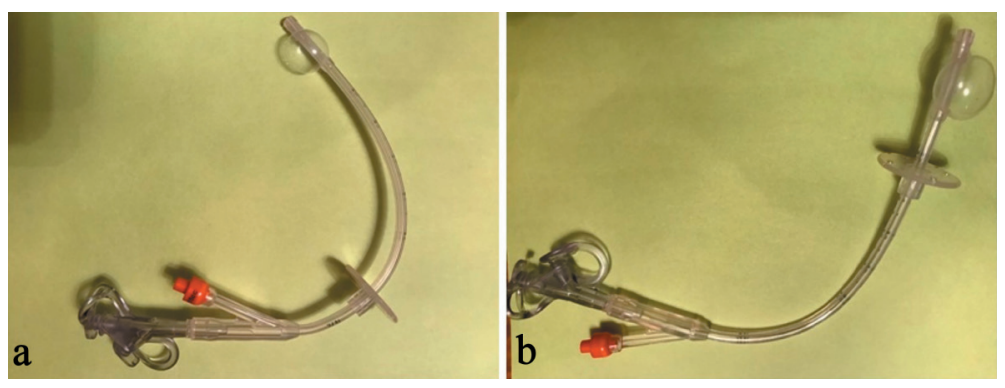

Figure 3. (a) In a migrated gastrostomy tube, the position of the external bolster from the tip and the balloon is usually more than $6 \mathrm{~cm}$. (b) The normal position of the external bolster from the tip and the balloon is usually less than $4 \mathrm{~cm}$.

through which to provide nourishment, water, and medications directly into the lumen of the stomach. Percutaneous endoscopic gastrostomy (PEG) is a well-recognized procedure for providing enteral feeding to those with swallowing disorders as well as long-term enteral nutritional support to those who need it. A PEG tube is a type of gastrostomy tube that is inserted percutaneously under endoscopic guidance.

Although it is generally believed to be a safe procedure, PEG tube placement has been associated with numerous potential complications $[3,4]$. Some of these complications may occur right away after PEG tube placement and include pneumoperitoneum, ileus, esophageal and gastric perforation, and injury to other intra-abdominal organs, such as the liver and large intestine. Other complications tend to develop much later, after the gastrostomy tract has matured, and include deterioration of the gastrostomy site, buried bumper syndrome, and formation of a colocutaneous fistula. Still other complications can occur at any time after PEG tube placement and include peristomal leakage, bleeding, ulceration, infection, inadvertent removal of the tube, and gastric outlet obstruction - a syndrome characterized by epigastric pain and postprandial vomiting secondary to mechanical obstruction.

In the setting of gastric outlet obstruction, the gastrostomy tube migrates forward into the pyloric channel or the duodenal bulb [1]. In fact, the gastrostomy tube can migrate as far as the second part of the duodenum, causing duodenal obstruction. Risk factors for these occurrences include the migration of an external bolster away from the abdominal wall, the migration of an inflated balloon (in the case of balloon gastrostomy tubes) through the pyloric channel, and the placement of the gastrostomy tube close to the pylorus [2].

Accordingly, a solution to prevent gastric outlet obstruction and duodenal obstruction is to appropriately position the external bolster (Fig. 3a, b), which should be placed so that 1 to $2 \mathrm{~cm}$ of forward and backward movement can be achieved $[4,5]$. Other key preventive measures include the use of correct technique during $\mathrm{PEG}$ tube placement as well as providing daily tube care $[4,5]$. Careful management of antithrombotic and anticoagulant agents is essential to prevent bleeding, and administration of broad-spectrum antibiotics before the procedure helps to prevent infection [4,5]. Early identification of complications allows for timely diagnosis and effective treatment. In the two cases above, the diagnosis likely would have been made earlier had the diminished length of the external component of the gastrostomy tube been noted. Marking the tube, regularly changing and examining the external component and local care and handling likely would have prevented these complications.

Barosa et al describe another case of an elderly woman who developed gastric outlet obstruction [6]. Her gastrostomy tube had been inadvertently pulled out a day earlier and a Foley catheter was placed in order to prevent the closure of the stoma. Fonseca et al describes a similar case of an elderly woman who developed persistent vomiting after a standard gastrostomy tube was replaced with a Foley catheter [7]. In the latter case, an upper endoscopy discovered the Foley catheter pulled into the duodenum causing gastric outlet obstruction. It was removed and replaced percutaneously under endoscopic guidance with a proper standard gastrostomy tube, permitting enteral feeding to be resumed. Both cases demonstrate that peristalsis can pull the balloon of the Foley catheter into the pyloric channel or the duodenum in the absence of an external bolster. Hawatmeh et al discuss another complication that can arise when a gastrostomy tube migrates forward into the second part of the duodenum [8]. They described two cases of acute pancreatitis secondary to gastrostomy tube balloon migration into the duodenum. In these cases, such migration led to obstruction of the ampulla of Vater, a disruption of the biliary flow and, ultimately causing acute pancreatitis. Likewise, Shah et al report two cases of acute pancreatitis induced by migrated gastrostomy tubes [9].

Previous case reports have classically described gastric outlet obstruction and duodenal obstruction as complications that are associated with insertion of Foley-type catheters. However, these cases are unique in that these patients had standard gastrostomy tubes with external bolsters that were present but had migrated away from the abdominal wall, allowing the gastrostomy tubes to migrate forward into the pyloric channel and the duodenum causing mechanical bowel obstruction. A clinical picture of abdominal pain, vomiting, and resistance to the attempt of percutaneous reposition should raise suspicion of gastrostomy tube migration through the pylorus.

\section{Conclusions}

In conclusion, PEG is a relatively safe procedure and major morbidity is uncommon. However, the number of patients who 
are dependent upon gastrostomy tube feedings is increasing across the world and complications are becoming increasingly frequent. In clinical practice, gastric outlet obstruction and duodenal obstruction secondary to gastrostomy tube migration is often misidentified as small bowel obstruction, leading to unnecessary medical tests and overly aggressive care. Physicians should be aware of and suspect gastric outlet obstruction and duodenal obstruction as rare late complications of PEG tube placement. Simple adjustment of the gastrostomy tube can resolve the problem in a cost-effective manner.

\section{Conflict of Interest}

None of the authors have any form of conflict of interest.

\section{Financial Support}

The authors received no financial support for the research, authorship and/or publication of this article.

\section{Author Contributions}

Conception and design: Jamil Shah, Tagore Sunkara, Prashanth Rawla, Vinaya Gaduputi; drafting of the article: Jamil Shah, Tagore Sunkara, Prashanth Rawla, Vinaya Gaduputi; critical revision of the article for important intellectual content: Jamil Shah, Tagore Sunkara, Prashanth Rawla, Vinaya Gaduputi; final approval of the article: Jamil Shah, Tagore Sunkara, Prashanth Rawla, Vinaya Gaduputi.

\section{References}

1. Clancy MJ, Hunter DC. Tube migration causing gastric outlet obstruction: an unusual complication of percutaneous endoscopic gastrostomy. Endoscopy. 2000;32(9):S58.

2. Chong VH. Gastric outlet obstruction caused by gastrostomy tube balloon. Indian J Gastroenterol. 2004;23(2):80.

3. Blomberg J, Lagergren J, Martin L, Mattsson F, Lagergren P. Complications after percutaneous endoscopic gastrostomy in a prospective study. Scand J Gastroenterol. 2012;47(6):737-742.

4. Hucl T, Spicak J. Complications of percutaneous endoscopic gastrostomy. Best Pract Res Clin Gastroenterol. 2016;30(5):769-781.

5. Rahnemai-Azar AA, Rahnemaiazar AA, Naghshizadian R, Kurtz A, Farkas DT. Percutaneous endoscopic gastrostomy: indications, technique, complications and management. World J Gastroenterol. 2014;20(24):7739-7751.

6. Barosa R, Santos C, Fonseca J. Gastric outlet obstruction: An unusual adverse event of percutaneous endoscopic gastrostomy. Rev Esp Enferm Dig. 2016;108(1):53-54.

7. Fonseca J, Nunes G, Patita M, Barosa R, Santos CA. Catheter traction and gastric outlet obstruction: a repeated complication of using a Foley catheter for gastrostomy tube replacement. Nutr Hosp. 2017;34(2):499-501.

8. Hawatmeh A, Alkhateeb A, Arqoub AA, Jumean K, Shaaban H. Gastrostomy tube migration complicated with acute pancreatitis: Two case reports with review of literature. Int J Crit Illn Inj Sci. 2016;6(1):48-50.

9. Shah AM, Shah N, DePasquale JR. Replacement gastrostomy tube causing acute pancreatitis: case series with review of literature. JOP. 2012;13(1):54-57. 